\title{
Use of multistage optimisation technique in formulation of strategies to reduce customer churn problem facing internet operators in Zimbabwe
}

\author{
Ndava Constantine Mupondo ${ }^{1,2, *}$, Brain Kusotera ${ }^{1,2}$, Desmond Mwembe ${ }^{1,2}$, Susan Maposa ${ }^{3,4}$ \\ ${ }^{1}$ Applied Mathematics Department, National University of Science and Technology, Bulawayo, Zimbabwe \\ ${ }^{2}$ National University of Science and Technology, NUST, Bulawayo, Zimbabwe \\ ${ }^{3}$ Mathematics Department, Midlands State University, Gweru, Zimbabwe \\ ${ }^{4}$ Midlands State University, MSU, Gweru, Zimbabwe
}

\section{Email address:}

constantine.mupondo@nust.ac.zw(N. C. Mupondo), bravokusotera@gmail.com(B. Kusotera), desmond.mwembe@nust.ac.zw(D.Mwembe),maposas@msu.ac.zw(S. Maposa)

\section{To cite this article:}

Ndava Constantine Mupondo, Brain Kusotera, Desmond Mwembe, Susan Maposa. Use of Multistage Optimisation Technique in Formulation of Strategies to Reduce Customer Churn Problem Facing Internet Operators in Zimbabwe. Science Journal of Applied Mathematics and Statistics, Vol. 1, No. 2, 2013, pp. 7-24. doi: 10.11648/j.sjams.20130102.11

\begin{abstract}
Internet is now considered indispensible in Zimbabwe's economic and social structures and world over. Jostling of operators to provide internet services has seen competition rise in Zimbabwe, leading to customer churn. The problem has tossed so many telecoms companies. Customer churn refers to the propensity to cease doing business with a company in a given time period. Companies are struggling to keep their customers from defecting. What then needs to be done? Formulation of robust set of strategies may be the solution to this headache. This paper seeks to come up with a model for strategy formulation, in order to establish strategies that reduce customer churn. The SWOT analysis, AHP and Linear Programming model were used to find the optimal strategy that would be implemented by the case study company, so as to reduce customer churn. The paper not only demonstrates strategy formulation using the model, but enlighten on the need to use quantitative analysis in strategy formulation.
\end{abstract}

Keywords: Customer Churn, SWOT Analysis, AHP, Linear Programming

\section{Introduction}

Communication industry is one of the fastest growing industries with $90 \%$ of the world's population using telecoms products [27]. The rapid growth of telecom users worldwide is also accompanied with increase in number of telecom providers, leading to fierce competition in this market. Moreover the introduction of Mobile Number Portability (MNP) and dongle use in various countries has also facilitated an easier mode for a customer to switch to another provider [8].

The propensity to cease doing business with a company in a given time period has become a problem for many firms [30]. In the internet service industry, reported global annual churn rates ranges from $21 \%$ to $63.3 \%$ [3]. In the wireless telephone industry, annual churn rate have been reported to range from $23.4 \%$ to $46 \%$ [2]. The world rates vary as different companies within different countries have different churn rates. Companies lose at least a quarter of their customers from one year to another. If no new customers are acquired then the average lifetime of an existing customer is equal to $1 / \mathrm{c}$, where $\mathrm{c}$ is the annual churn rate. For the company with $25 \%$ churn, that means an average lifetime of 4 years for the customer, whereas a churn rate of $50 \%$ has 2 years lifetime value [19].

Recent reports on global mobile churn indicates that mobile customer loyalty has fallen to all time low, with the average customer now switching provider every 27 months [10]. This average is more than twice as frequently as a decade ago [23]. In 2011 global churn reached a record high of $44 \%$. In Asia pacific, the churn rate nears $100 \%$ per year [1]. Churn happens in both directions, to and from the operator. In Zimbabwe the introduction of mobile internet (that is served via modems) makes it easier for a customer to switch from one operator to another operator [20]. This switching is referred to as customer churn. Some of the causes of customer churn are switching costs, 
dissatisfaction/service quality and customer status [18].

Because of competition in the communications sector, Mobile internet operators in Zimbabwe are finding it hard to keep their customers and they are losing their customers to other operators. Not only in Zimbabwe but companies globally are also experiencing the problem of customer churn. Entrance of new service providers has stiffened competition. The focus of communication companies has therefore shifted from building a large customer base into keeping customers in house.

\subsection{Purpose of the Study}

The problem is that mobile internet operators (Case: Powertel communications) are facing the problem of customer churn and is affecting revenue growth and profitability. The research proposes to use SWOT analysis and Analytic Hierarchy Process-Linear Programming model to come up with an optimal strategy, from a set of strategies, to reduce customer churn.

\subsection{Objectives}

The objectives of this research are to:

(i) Come up with an optimal strategy that reduce customer churn.

(ii) Come up with weights for SWOT variables in terms of their importance in reducing customer churn and corresponding SWOT factors in terms of their importance within their categories of SWOT, using SWOT analysis, AHP and Linear Programming.

(iii) Come up with strategies that minimize effects of SWOT factors on customer churn and their respective weights using AHP-Linear Programming model.

(iv) Selecting an optimal strategy that reduces customer churn from the AHP-ranked strategies.

\section{Theoretical Framework}

\subsection{Introduction}

Customer churn is often treated like flu: management assumes the root cause of the problem can be eliminated and that the best it can hope for is to minimize its symptoms. But in the same way that medical breakthrough empowers physicians to attack the virus directly, companies can diagnose and repair the root causes of customer churn and the problem can be cured.

It is generally accepted that there is a positive relationship between market share and profitability [30]. This means that as the market share increases, profits increase. Also as the market share decreases, profits also decrease. This means that there is an inverse relationship between customer churn and growth and profitability.

\subsection{Customer Churn}

Customer churn occurs when a customer (player, subscriber, user, etc.) ceases his or her relationship with a company. Online businesses typically treat a customer as churned once a particular amount of time has elapsed since the customer's last interaction with the site or service. The full cost of customer churn includes both lost revenue and the marketing costs involved with replacing those customers with new ones. Reducing customer churn is a key business goal of every telecommunications business. [32], defined customer churn as the number of net deactivations (that is gross adds minus net adds) divided by the average number of subscriptions during the year.

\subsection{Customer Churn Rate}

Refers to the rate at which customers terminate their relationships with a company over a given period of time. For example, if 5 customers in 100 discontinue paying their subscriptions every month, the churn rate is $5 \%$. The churn rate contrasts with the growth rate, which, in this case, is defined as the number of new clients or customers. If a company is to grow, the growth rate must consistently exceed the churn rate [32]. The churn rate is important in the telecommunications industry, where several companies operate in a geographical area and compete for customers.

[32], churn can be shown as follows:

$$
\text { Monthly churn }=\frac{C O+A I-C I}{C O}
$$

Where:

$\mathrm{CO}=$ number of customers at the start of the month.

$\mathrm{C} 1=$ number of customers at the end of the month.

A1 $=$ Gross new customers during the month.

\subsection{Causes of Customer Churn}

In an intensely competitive environment, customers receive numerous incentives to switch to some other operators and encounter numerous disincentives to stay with the current operator. There are many reasons to leave a provider but there might be just one reason to stay [32]. Some of the reasons include price, service quality, fraud, brand visibility, privacy concerns, lack of features/innovativeness, new technology introduced by competitors, new competitors entering the market, billing or service disputes, strategy, etc.

\subsection{SWOT Analysis}

[22], SWOT is a widely used technique whose purpose is to provide information about the internal and external variables that should be taken into account in the formulation of strategies for an organization. The variables of interest are grouped in four categories, usually identified with the letters $\mathrm{S}, \mathrm{W}, \mathrm{O}$ and $\mathrm{T}$. The following is the explanation of the SWOT variables:

S - Variables associated with factors in which the organization shows certain strength; variables an organization should take advantage of in the growth and development of the organization.

W - As opposed to the previous group, this group 
contains variables associated with factors in which the organization shows certain weakness; variables that, unless be corrected or improved, could impede or make difficult the growth and development of the organization.

$\mathbf{O}$ - Variables associated with aspects that can be seen as opportunities that the organization could take advantage of for its growth and development.

T - Variables that could represent a threat to the growth and development of the organization; variables whose effects look advisable to prevent or neutralize.

It is clear that this information would allow us to take advantage of the strengths and opportunities, and to undertake actions for a better handling of the threats, as well as for lessening the effect of the weakness factors. All these should be considered as objectives for any strategic plan.

The SWOT technique has proved to be of great help in the understanding of the environment for organizations and, consequently, in the strategic planning. However, experience has shown that often its usefulness has been sub valued by limiting it to the stage of strategies design. Its value could be increased substantially by complementing it with techniques for the evaluation of these strategies, and for the selection of the most convenient one for the organization.

\subsection{Analytic Hierarchy Process}

The AHP developed by [24] is a robust and flexible multi-criteria decision analysis methodology. Saaty had worked earlier in his carrier at several research projects for Arms Control and Disarmament Agency at the U.S. Department of State and also at Wharton School. During his research projects he discovered that people often had many issues when it comes down to making certain decisions or to prioritize some points of their work. This motivated Saaty to create a new tool so that they would be able to make more complex decisions easier [11].

Maybe the best things about the Analytic Hierachy Process are that it takes an approach towards the decision making from the rational and intuitive point of view and gives the ability to select the best solution from various alternatives. According to [26], the reason why this kind of hierarchy is applied, is because it is possible to judge the importance of the elements in a given level with respect to some or all of the elements in the adjacent level above. The AHP structures the decision problem into a hierarchy model which consists of three different layers [26].

AHP uses an interactive hierarchical structure for multi-objective decision-making (MODM). [11], defined AHP as a decision and forecasting method giving the percentage distribution of decision points in terms of the factors affecting the decision.

AHP has become preferred by decision-makers as a reliable tool since it ranks the evaluation factors according to their relative importance, then assesses the decision points for every factor and, finally, has a mathematical method combining these two stages [15]. AHP is used in the decision making to estimate the likelihood of an event, by establishing relative importance of each contributing factors [9].

The structuring complexity of AHP model is based on an idea that complex problems should be presented in such a way that even people without formal training could understand it. The simplicity of AHP comes up from the hierarchical structuring of complexity into homogeneous clusters of factors. The hierarchical point of view taken to AHP gives it an ability to be understood quickly by human mind and therefore AHP can also be seen as a friendly format of displaying complex situation for human mind [11]. The most notable function which distinguishes Analytic Hierarchy Process from many other analytical processes is its ability to measure and synthesize the multitude of factors in a hierarchy. This is very important as there are many different tools and processes which can be used to create analysis, but a few which can be used for producing any kind of synthesis out of this analysis [11].

The methodology combines both qualitative and quantitative approaches. In the qualitative sense, it decomposes an unstructured problem into a systematic decision hierarchy. It then uses mathematical synthesis to employ pair-wise comparison to determine the local and global priority weights and the overall ranking of the alternatives. The methodology quantifies the qualitative factors with a scale called Saaty's 9 - point scale.

Table 1. The fundamental $1-9$ scale

\begin{tabular}{ccc}
\hline $\begin{array}{c}\text { Intensi } \\
\text { ty }\end{array}$ & Definition & ExplanationColumn2 \\
\hline 1 & Equal Importance & $\begin{array}{c}\text { Two activities contribute equally to the } \\
\text { objective }\end{array}$ \\
3 & Moderate Importance & $\begin{array}{c}\text { Experience and judgments slightly } \\
\text { favor one activity over another } \\
\text { Experience and judgments strongly } \\
\text { favor one activity over another Row3 } \\
\text { An activity is strongly favored and its } \\
\text { dominance is demonstrated in practice } \\
\text { The evidence favoring one activity } \\
\text { over another is of the highest possible } \\
\text { order of affirmation }\end{array}$ \\
9 & Essential or Strong & Importance demonstrated \\
$2,4,6,8$ & Intermediate values & When compromise is needed \\
\hline
\end{tabular}

The fundamental scale differs from many other scales because it doesn't measure how many times one is larger than the other, but tries to help to show how much of a fraction the one is larger than the other. So the fundamental table should be read in a way that would reflect the slight differences between the two objects [25].

The fundamental scale describes the small differences of importance between two objectives; it is very hard to determine a strict line between intensity of importance. So according to[24], to get more distinction between the importance it is widely agreed to leave out the $2^{\text {nd }}, 4^{\text {th }}, 6^{\text {th }}$ and $8^{\text {th }}$ intensity of importance out and use only the uneven levels. In this way the distinction between two factors can be done more specifically and easily than just by guessing the distinction in one way or the other 
[25].

\subsection{Combined Uses of SWOT-AHP}

The AHP is largely used to make the factors in SWOT analysis more measurable via providing them with analytical priorities and to support the strategic planning process qualitatively.

The combined use of the AHP and SWOT analysis has been widely used to support strategic decision-making processes such as institutional situation analysis and strategy selection [13]; strategic selection in defense sector [15]; developing collaborative strategy in health sector [22]; strategy development in industry sector [27].

By integrating SWOT with AHP, not only the mutual weighting of SWOT factors, but also the evaluation of alternative strategic decisions can be integrated with ordinary SWOT analysis. The most crucial weakness of SWOT can be avoided $[9,34]$. SWOT-AHP is being applied to increase and improve the information basis of the strategic planning processes, not only provides a robust decision support, but also provides an effective framework for learning in any case of strategic decision support. SWOT-AHP is carried out in five stages (Figure 1) [16,34]. These stages are:

(i) SWOT analysis: The SWOT groups - Strength, Weaknesses, Opportunities, and Threats - are created. SWOT factors of each SWOT group will be included in the analysis are ranked as neutral as possible.

(ii) Pair-wise comparisons between SWOT factors are performed using [26] nine point scale separately within each SWOT group. The comparisons are used as input to the scope and then the priorities of SWOT factors are calculated using eigenvalue approach of AHP technique.

(iii) Relative priorities of $\mathrm{S}, \mathrm{W}, \mathrm{O}$ and $\mathrm{T}$ factor group are determined by pair-wise comparisons.

(iv) Evaluating the strategy alternatives for each factor. At this stage, the relative priority value of each SWOT group is separately multiplied by the relative priority of each of the SWOT factors in this group. Thus, the overall priority value of the each SWOT factor in related SWOT group is derived. This process is repeated for each SWOT group. Finally the overall priority values of all the SWOT factors of which total values of all the SWOT factors of which total value is equal to one are obtained.

(v) General priority calculations for the strategy alternatives.

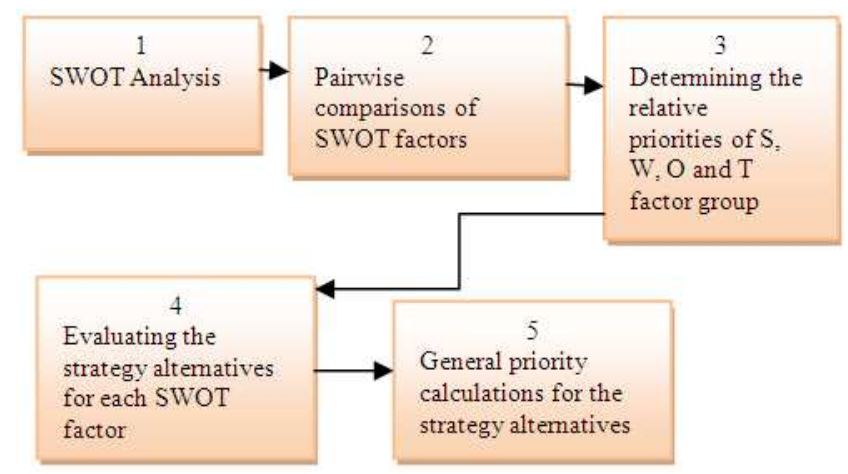

Figure 1. Application stages of SWOT-AHP

\subsection{AHP and Linear Programming Model for Weights Calculations}

[7] presented a novel approach based on linear programming to generate a priority vector within the framework of the Analytic Hierarchy Process. [7] used two stage linear programming and in his paper consistency index was expressed as a function of the first stage linear programming objective function value. According to the authors, the value of the objective function $z^{*}$ is the minimum of the sum of logarithms of positive errors in the natural space. Therefore the objective function minimizes the geometric mean of all errors greater than $1\left(\varepsilon_{i j} \geq 1\right)[7]$.

The objective function of the first stage linear programming is a measure of inconsistency in the pair wise comparison matrix. The greater the value of the objective function, the more inconsistent the pair wise judgment may be.

When we solve the first-stage linear program, the solution set consists of all priority vectors that minimize the product of all errors $\varepsilon_{i j}$. It is possible that there are multiple optimal solutions to the first-stage model. In the second stage, we solve a linear program that selects from this set of alternative optima, the priority vector that minimizes the maximum of errors $\varepsilon_{i j}$ [7].

[7] defined the consistency index within the LP framework as:

$$
C I_{L P}=\frac{2 Z^{*}}{n(n-1)}
$$

Where:

$C I_{L P}=$ the consistency index within the LP framework.

$z^{*}=$ the value of the objective function that minimizes the sum of logarithms of errors.

$n=$ the order of the matrix.

$C I_{L P}$ is the average value of $z_{i j}$ for elements above the diagonal in the comparison matrix. In preliminary computational experiments, $C I_{L P}$ and $C I$ seem to be highly correlated [7].

The advantages of the LP approach over the eigenvector 
approach are that it is simple to understand and permits for sensitivity analysis. In particular, a decision maker might be interested in answering the following questions. Which entry in the pair wise comparison matrix should be changed? [7] noted that when traditional approaches like eigenvector approaches are used, it is difficult to answer these questions.

However, the methodology that was used by the authors tests for consistency on first stage linear programming of which after carrying out some tests using dummy data it will not be the case. Consistency must be checked in second stage linear programming. Despite these limitations, the researcher gives credit to the authors for mooting such a valuable tool.

\subsubsection{The Mathematical Model}

The model used by the researcher started with the hierarchy for the problem and has been structured in four levels. The first level, as usual, is the goal to be achieved by the decision; the next level is constituted by the four groups of factors as defined by the SWOT technique: Strengths (S), Weaknesses (W), Opportunities (O) and Threats (T); the third level is constituted by the factors included in each one of the four groups of the previous level; and finally, the fourth level is constituted by the strategies that should be evaluated and compared.

The mathematical equation that calculates global values for the strategies to facilitate ranking used by the researcher is defined as follows;

Let $V_{j}$ be the global (relative) value of Strategy $j$, $j=1, \ldots ., n$, we can write:

$$
V_{j}=w_{s} \sum_{i=1}^{m s} w_{s i} U_{s i, j}+w_{w} \sum_{i=1}^{m w} w_{w i} U_{w i j}+w_{o} \sum_{i=1}^{m w} w_{o l} U_{0 i, j}+w_{T} \sum_{i=1}^{m T} w_{T i} U_{T i, j}
$$

Where:

$\left(w_{s}, w_{w}, w_{o}, w_{T}\right)$ represent relative importance of each group of factors $(\mathrm{S}, \mathrm{W}, \mathrm{O}$ and $\mathrm{T})$ for the achievement of the organizational goal.

$\left(w_{s 1},---, w_{s m s}\right)$ represent relative importance of the Strengths factors $\left(S_{1}, S_{2},---S_{m s}\right)$ within their group $(S)$ and the statement holds also for $\left(w_{w 1},---w_{w m s}\right)$,

$\left(w_{o 1},---w_{\text {omo }}\right),\left(w_{T 1},---w_{t m t}\right)$, that is for the

Weaknesses, Opportunities and Threats factors within their own group (W, O and T).

For any Strategy $j,(j=1,2, \ldots, n)$ we have:

- $U_{s i, j}$ Representing efficiency of Strategy $j$ in taking advantage of the strength factor $S_{i}(i=1,2,---, m s)$.

- $U_{w i, j}$ Representing efficiency of Strategy $j$ in lessening the effects of the weakness factor $w_{i} \quad(i=1,2,---, m w)$.

- $U_{o i, j}$ Representing efficiency of Strategy $j$ in taking advantage of the opportunity factor $O_{i}$ $(i=1,2,---, m o)$.

- $U_{T i, j}$ Representing efficiency of Strategy $j$ in facing the threat factor $T_{i}(i=1,2,---, m t)$.

All these six strategies were evaluated and compared in order to select the best one for the organization, with the main objective of its growth and development for the three years. In addition, the results could provide a guide for how to split the efforts and resources for attending the rest of the strategies.

Responsible for the decision-making were the same seven actors in charge of the SWOT study and of the strategies design. As usual in these processes, there was no agreement with regard to the best strategy, and the use of a quantitative technique (Analytic Hierarchy Process and Team Expert Choice) was recommended.

\section{Methodologies for Analysis}

Optimization models have become useful in solving multi criteria decision problems.

They have been used in comparing, selecting, planning, implementing and optimizing problems. This paper presents the models to be used in strategy formulation, to reduce customer churn for telecoms companies (Case: PowerTel Communications Zimbabwe). The researchers will use results from SWOT analysis and AHP- Linear Programming, to assess and select strategies in an informed way. The SWOT analysis will be used to come up with Strengths, Weaknesses, Opportunities and Threats factors. The AHPLinear programming combination will be used to calculate weights for criteria and alternatives per each level.

\subsection{SWOT Analysis}

It is a technique whose purpose is to provide information about the internal and external variables that should be taken into account in the formulation of strategies for an organization.

Let:

S-strengths

W-weaknesses

O-opportunities

T-threats

$S_{1}, S_{2},---, S_{m s}$ be the group of factors under the strengths category.

$w_{1}, w_{2},--, w_{m w}$ be the group under the weakness category.

$o_{1}, O_{2},--, O_{m o}$ be the group under opportunities category.

$T_{1}, T_{2},---, T_{T s}$ be the group under threats category.

SWOT analysis helps in coming up with strategies to be considered to reduce the effect of SWOT factors so as to reduce customer churn.

Let: 
Strategy $j$ be $S_{j}, j=1,2, \ldots \ldots, n$.

\subsection{Two Stage Linear Programming}

Two stage linear programming combines well with AHP and it generates a priority vector within the framework of the Analytic Hierarchy Process. The advantages of the LP approach over the Eigen-vector approach is that it is simple to understand and permits for sensitivity analysis. In particular, a decision maker might be interested in answering the following questions. Which entry in the pair wise comparison matrix should be changed? When traditional approaches like Eigen vector approaches are used, it is difficult to answer these questions.

Suppose:

$$
\bar{w}=\left(\begin{array}{c}
w_{1} \\
w_{2} \\
\cdot \\
w_{n}
\end{array}\right)
$$

is the vector of weights associated with matrix A.

Let:

$\frac{w_{i}}{w_{j}}=a_{i j} \varepsilon_{i j}, \quad$ for $i, j=1,2, \ldots \ldots \ldots . ., n:$

Therefore

$\ln w_{i}-\ln w_{j}=\ln a_{i j}+\ln \varepsilon_{i j}$

Where:

$\mathcal{E}_{i j}$ is the error of estimating relative preference $a i j$

$w_{i}$ weight of element $i$.

$w_{j}$ weight of element $j$.

If $\ln a_{i j}=0$, then the decision maker is consistent.

\subsubsection{Decision Variables}

The decision variables are given by:

$w_{i}$ weight of element $\mathrm{i}$

${ }^{w_{j}}$ weight of element $\mathrm{j}$

$\varepsilon_{i j}$ error factor in estimating $\mathrm{a}_{\mathrm{ij}}$

\subsubsection{Transformed Decision Variables}

The two stage linear programming uses transformed decision variables.

$$
\begin{aligned}
& x_{i}=\ln w_{i} \\
& x_{j}=\ln w_{j} \\
& y_{i j}=\ln \varepsilon_{i j} \\
& z_{i j}=\left|y_{i j}\right|
\end{aligned}
$$

Where:

$y_{i j}$ - is the natural logarithm of the error factor in estimating $a_{i j}$.

$z_{i j}$ - is the absolute value of the natural logarithm of error factor in estimating $a_{i j}$.

$$
\begin{aligned}
& \min \sum_{i=1}^{n-1} \sum_{j=i+1}^{n} z_{i j} \\
& s t: \quad x_{i}-x_{j}=\ln a_{i j}, i, j=1,2,3, \ldots \ldots \ldots . ., n ; \quad i \neq j \\
& \quad z_{i j} \geq y_{i j}, \quad i, j=1,2,3, \ldots \ldots \ldots \ldots, n ; i<j \\
& z_{i j} \geq y_{j i}, \quad i, j=1,2,3, \ldots \ldots \ldots \ldots, n ; i<j \\
& \quad x_{1}=0 \\
& \quad x_{i}-x_{j} \geq 0, \quad i, j=1,2,3, \ldots \ldots \ldots \ldots, n ; a_{i j}>1 \\
& \quad x_{i}-x_{j} \geq 0, \quad i, j=1,2,3, \ldots \ldots \ldots \ldots, n ; a_{i k}>a_{j k}, \forall k ; \\
& a_{i a}-a_{i a}, \quad \exists q \\
& z_{i j} \geq 0, i, j=1,2,3,---, n \\
& x_{i}, y_{i j} \text { unrestriced } i, j,=1,2,3 .---n .
\end{aligned}
$$

In the comparison matrix $A$, if $\mathrm{a}_{\mathrm{ij}}$ is overestimated (that is, the decision maker's judgment of entry $i$ versus entry $j$ is greater than the true value), then $a_{j i}$ is underestimated. $a_{j i}$ is the reciprocal value of $a_{i j}$. We then have:

$$
\begin{aligned}
& \varepsilon_{i j}=\frac{1}{\varepsilon_{j i}} ; \quad i, j=1,2,3, \ldots \ldots ., n \\
& \text { or } \\
& y_{i j}=\frac{1}{y_{j i}} ; \quad i, j=1,2,3, \ldots \ldots ., n
\end{aligned}
$$

By obtaining the greater of $y_{i j}$ and $y_{j i}$, set of constraints:

$$
\begin{aligned}
& z_{i j} \geq y_{i j}, \quad i, j=1,2, \ldots \ldots \ldots \ldots, n ; \\
& z_{i j} \geq y_{j i}, \quad i, j=1,2, \ldots \ldots \ldots \ldots, n ;
\end{aligned}
$$

identify for each $i$ and $j$ the element that is overestimated and the magnitude of error.

Since the solution set to constraints:

$$
\begin{array}{ll}
x_{i}-x_{j}=\ln a_{i j}, & i, j=1,2,3, \ldots \ldots \ldots, n ; i \neq j \\
z_{i j} \geq y_{i j}, & i, j=1,2,3, \ldots \ldots \ldots, n ; i<j \\
z_{i j} \geq y_{j i}, & i, j=1,2,3, \ldots \ldots \ldots, n ; i<j
\end{array}
$$

is infinitely large, any value $w_{i}$ can be fixed without loss of generality. This is done in constraint $\left[x_{1}=0\right]$ by setting $w_{i}$ $=1$.

The final weights can be normalized to sum to one. Normalization implies adding the final weights from the second stage linear programming, using the vector normalization concept. There are two desirable properties of a pair wise comparison matrix:

\subsubsection{Element Dominance (ED)}

ED is preserved when $a_{i j} \geq 1$ implies $w_{i} \geq w_{j}$. In the first stage LP, ED is preserved through $\left[x_{i}-x_{j} \geq 0 ; i ; j=1\right.$, $\left.2, \ldots \ldots, n ; a_{i j}>1\right]$.

\subsubsection{Row Dominance (RD)}

$\mathrm{RD}$ is preserved if $a_{i k} \geq a_{j k}$, for all $k$ and $\mathrm{a}_{\mathrm{ik}}>a_{j k}$, for some $\mathrm{k}$, implies $w_{i} \geq w_{j}$. In the first stage LP, RD is enforced through constraint $\left[\mathrm{x}_{\mathrm{i}}-\mathrm{x}_{\mathrm{j}} \geq 0 ; i, j=1 ; 2 \ldots n ; a_{i k}>\right.$ $a_{j k}$, for all $\mathrm{k} ; a_{i q}>a_{j q}$ for some q].

$\mathrm{x}_{\mathrm{ij}} ; \mathrm{y}_{\mathrm{ij}}$ are unrestricted since they are logarithms of positive 
real numbers, therefore in LINDO they have to be stated as free variables. Thus the objective function in the first stage linear programming minimizes the sum of positive errors in the natural logarithm space.

The purpose of first stage LP is to provide bound for consistency. Thus the objective function is a measure of inconsistency in the pair-wise comparison matrix.

That is, the greater the value of the objective function, the more inconsistent is the matrix. The first stage Linear Programming produces infeasible solution if the comparison matrix is inconsistent.

If the matrix is inconsistent, this means that the decision maker's judgment is incorrect and needs review so as to ensure unbiased results. This means the decision maker must start all over again.

\subsubsection{Second Stage Linear Programming}

When first stage LP is solved, the solution set consists of all priority vectors that minimize the product of all errors $(\varepsilon)$. It is possible to have multiple optimal solutions to the first model. Second stage LP selects from this set of alternatives the optimal priority vector that minimizes the maximum of errors $(\mathcal{E})$. The objective function in the second stage Linear Programming is a minimization of the maximum of $z_{i j}, i, j=1,2, \ldots \ldots ., n . z_{i j}$ is the absolute value of the natural logarithm of error factor in estimating $a_{i j}$

The second stage LP is given by:

$$
\begin{array}{ll}
\min & z_{\max } \\
s t: & \sum_{i=1}^{n-1} \sum_{j=i+1}^{n} z_{i j}=z_{\max } \\
& x_{i}-x_{j}=\ln a_{i j}, \quad i, j=1,2,3, . ., n ; i \neq j \\
& z_{i j} \geq y_{i j}, \quad i, j=1,2,3, \ldots, n ; i<j \\
& z_{i j} \geq y_{j i}, \quad i, j=1,2,3, \ldots, n ; i<j \\
& z_{\max } \geq z_{i j}, \quad i, j=1,2,3, \ldots, n ; \\
& x_{1}=0 \quad i, j=1,2,3, \ldots, n ; a_{i j}>1 \\
& x_{i}-x_{j} \geq 0, \quad i, j=1,2,3, \ldots, n ; a_{i k}>a_{j k}, \forall k ; \\
& x_{i}-x_{j} \geq 0, \quad \\
& a_{i q}>a_{j q}, \exists q
\end{array}
$$

Constraint $\left[\sum_{n=1}^{n-1} \sum_{j=i+1}^{n} z_{i j}=z_{\max }\right]$ ensures that only those solution vectors that are optimal in the first stage LP are feasible in the second stage model. Constraint $\left[z_{\max } \geq z_{i j}, \quad i, j=1,2,3, \ldots \ldots \ldots, n\right]$

finds the maximum values of errors. The objective function minimizes $z_{\max }$. Constraint $\left[z_{\max } \geq 0\right]$ is the non negativity constraint for $z_{\max }$. All other constraints in the second stage LP are identical to those in the first stage LP.

\subsection{Consistency Check} if;

A pair wise comparison matrix is consistent if and only
Consistency ratio $(\mathrm{CR})=\frac{C I_{L P}}{R I} \leq 0.1$

Where: $\quad C I_{L P}=\frac{2 z^{*}}{n(n-1)}$

is the consistency index within the LP framework.

$z^{*} \mathrm{RI}$ is the random index obtained from the random index table depending on the order of the matrix.

is the second stage Linear Programming objective function value.

Table 2. Random index table

\begin{tabular}{c|cccccccccc}
\hline $\mathrm{n}$ & 1 & 2 & 3 & 4 & 5 & 6 & 7 & 8 & 9 & 10 \\
$\mathrm{R} 1$ & 0.00 & 0.00 & 0.58 & 0.9 & 1.12 & 1.24 & 1.32 & 1.41 & 1.45 & 1.49 \\
\hline
\end{tabular}

A consistency level less or equal to 0.1 has been considered as desirable [24].

\subsection{Global Values for Strategy}

Global values for strategies are obtained using the formula below. If we define $\mathrm{V}_{\mathrm{j}}$ as the global (relative) value of the strategy $j ; j=1,2 \ldots n$, then:

$$
v_{j}=w_{s} \sum_{i=1}^{m s} w_{s i} u_{s i, j}+w_{w} \sum_{i=1}^{m w} w_{w i} u_{w i, j}+w_{o} \sum_{i=1}^{m o} w_{o i} u_{o i, j}+w_{T} \sum_{i=1}^{m t} w_{T i} u_{T i, j}
$$

Where:

$\left(w_{s}, w_{w}, w_{o}, w_{T}\right)$ represent relative importance of each group of factors $(\mathrm{S}, \mathrm{W}, \mathrm{O}$ and $\mathrm{T})$ for the achievement of the organizational goal.

$w_{s 1}, \ldots \ldots . ., w_{s m s}$ Represent relative importance of the Strengths factors $s_{1}, \ldots \ldots \ldots . . ., s_{m s}$ within their group (S) and the statement holds also for

$\left(w_{w 1}, \ldots \ldots \ldots ., w_{w m s}\right),\left(w_{o 1}, \ldots \ldots \ldots \ldots . ., w_{o m o}\right),\left(w_{T 1}, \ldots, w_{t m t}\right)$, that is for the Weaknesses, Opportunities and Threats factors within their own group (W, $\mathrm{O}$ and $\mathrm{T})$.

For any Strategy $\mathrm{j} ;(\mathrm{j}=1,2 \ldots \mathrm{n})$ we have: $U_{s i, j}$ Representing efficiency of Strategy $\mathrm{j}$ in taking advantage of the strength factor $s_{i}(i=1,2 \ldots m s)$ : $U_{w i, j}$ Representing efficiency of Strategy $\mathrm{j}$ in lessening the effects of the weakness factor $w_{i}(i=1,2, \ldots \ldots, m w)$ :

$U_{o i, j}$ Representing efficiency of Strategy $\mathrm{j}$ in taking advantage of the opportunity factor $\mathrm{o}_{\mathrm{i}}(\mathrm{i}=1,2 \ldots \mathrm{mo})$ : $U_{T i, j}$ Representing efficiency of Strategy $j$ in facing the threat factor $T_{i}(i=1,2 \ldots m t)$ :

Strategy with the highest $V_{j}$ is the one selected and prioritized first. Results for global evaluation made by decision makers for the strategies are combined and the normalized values corresponding to the strategies obtained using the vector normalization process.

\subsection{Survey Design and Data Collection}

The data used in this study were collected from Powertel Communications Zimbabwe's branches through out the country. The process is in twofold; the qualitative and the quantitative phases. The qualitative phase in this study involves collection of data on SWOT factors in relation to 
their effect on customer churn and list of possible strategies that can be used to minimize or reduce customer churn. The quantitative phase involves the collection of numerical data on pair-wise judgments. Data collection process requires company executives' participation and commissioning of the passage of company's internal information.

Face to face interviews- The tool allows for personal two way communication and makes it possible to gather more information. Data on pair wise judgments require the presence of the researcher for two stage Linear Programming computations; so as to reduce bias, provide guidance on how to rate different factors and ensure consistency in judgments. If the judgments are inconsistent, alterations may be made on the pair wise judgments.

The company under consideration has five departments, so the research requires collection of data from a collection of all company executives and all subordinate workers. These executives provide qualitative and quantitative information. Judgments are to be based on Saaty's fundamental 1-9 scale. Clients were also sampled to give their responses on the quality of services they receive and areas of possible improvements.

\section{Results and Analysis}

\subsection{Weights for SWOT Variables}

Weights for SWOT variables, in terms of their importance, in the achievement of organizational goal were calculated using Linear Programming, solved using LINDO. The LP and the results are presented in Appendix 2. Below is a table of weights obtained:

Table 3. Weights for SWOT variables

\begin{tabular}{c|c|c|c}
\hline$w_{s}$ & $w_{w}$ & $w_{o}$ & $w_{T}$ \\
\hline 0.549 & 0.091 & 0.300 & 0.060 \\
\hline
\end{tabular}

The pair wise judgment has a consistency ratio of $\mathrm{CR}=$ 0.049907074, which is less than 0.1 and is considered desirable under the AHP process. From the table, Strengths are considered as important in reducing customer churn with a rating of $w_{s}=0.549$, followed by opportunities $\left(w_{o}=\right.$ $0.300)$, then comes Weaknesses $\left(w_{w}=0.091\right)$ and lastly Threats $\left(w_{T}=0.060\right)$. This means that the company must take advantage of its Strengths and combat threats in the best possible way.

\subsection{Weights for SWOT Factors in Terms of their Importance within their Group/Category}

Weights for SWOT factors, in terms of their importance within their groups, were calculated using Linear Programming, solved using IINDO. Below is a table of the weights obtained:
Table 4. Weights for SWOT factors in terms of their importance within their group/category

\begin{tabular}{cccccccc}
\hline Strength Factors & $w_{s 1}$ & $w_{s 2}$ & $w_{s 3}$ & $w_{s 4}$ & $w_{s 5}$ & $w_{s 6}$ \\
\hline $\mathrm{CR}=0.074531935$ & 0.108 & 0.108 & 0.216 & 0.108 & 0.027 & 0.432 \\
Weakness Factors & $w_{w 1}$ & $w_{w 2}$ & $w_{w 3}$ & $w_{w 4}$ & $w_{w 5}$ & $w_{w 6}$ \\
$\mathrm{CR}=0.074531935$ & 0.361 & 0.181 & 0.036 & 0.060 & 0.181 & 0.181 \\
Opportunities Factors & $w_{o 1}$ & $w_{o 2}$ & $w_{o 3}$ & $w_{o 4}$ & $w_{o 5}$ & $w_{o 6}$ \\
$\mathrm{CR}=0.07106215$ & 0.034 & 0.172 & 0.172 & 0.138 & 0.069 & 0.414 \\
Threats Factors & $w_{T 1}$ & $w_{T 2}$ & $w_{T 3}$ & $w_{T 4}$ & $w_{T 5}$ & $w_{T 6}$ \\
$\mathrm{CR}=0.059065161$ & 0.073 & 0.073 & 0.291 & 0.055 & 0.218 & 0.290 \\
\hline
\end{tabular}

In the group of strengths, a consistency ratio of, $\mathrm{CR}=$ 0.074531935 was obtained indicating consistency in pair wise judgments, since it is less than 0.1 . Strengths factor; 'Prices' $=w_{s 6}=0.432$, is the most important. This means that, it should be a priority for the company to review prices. Strength factor; 'Interconnected to international internet bandwidth providers at two points' $=w_{s 3}=0.216$, is second important, meaning it should be prioritized after pricing. Following in the perking order are the three factors ('Optic fiber backbone on ZETDC lines (less prone to vandalism - high availability)' $=w_{s 1}$, 'Wireless access network (CDMA network)' $=w_{s 2}$ and 'Technical expertise' $=w_{s 4}$ having the same rating of $\$ 0.108$. The least strength factor is 'Brand Visibility' $=0.027$, which should receive minimum attention though its percentage $(2.7 \%)$ reflects its importance as an aggregatory factor.

In the group of Weaknesses, a consistency ratio of, $\mathrm{CR}=$ 0.074531935 , was obtained which is less than 0.1 indicating consistency in the pair wise judgments. 'Low geographical network coverage' $=w_{w 1}=0.361$ is the number one weakness factor of the company and it should be reduced by expanding the network. Following up are three factors ('Funding $=w_{w 2}$, 'Products shortages' $=w_{w 5}$ and 'Lack of innovation' $=w_{w 6}$ having the same rating 0.181 . This means that, this set of factors must receive considerable attention to lessen their effect. Weakness factor; 'Delays in commissioning of a billing system' = $w_{w 4}=0.06$ lie third in terms of its importance within weakness factors group. The company should immediately commission for a billing system. Lastly, 'Delays in commercial launch of VoIP services' $=w_{w 3}=0.036$, lie fourth in terms of its importance in weaknesses category. This factor may be the last one to be looked at.

In the category of opportunities, a consistency ratio of, 
$\mathrm{CR}=0.07106215$, was obtained and is less than 0.1 meaning the pair wise comparison matrix for opportunities factors is consistent. Factor;

POTRAZ installing passive infrastructure in remote areas' $=w_{o 6}$ has the highest ranking of 0.414 , meaning the company has to first take advantage of the POTRAZ initiative. Factors; ' Dollarization of the economy' $=w_{o 2}$ and 'look east policy - have Asian equipment vendors locally' $=w_{o 3}$, have the same rating of 0.172 and are second in the rankings. This means that prioritization of these factors comes second after the company has taken advantage of the POTRAZ initiative. Number three on the rankings is the factor 'A big market' $=w_{o 4}$ with a rating of 0.138 and is third important in terms of prioritization. Factors; 'Increasing acceptance of bandwidth/ ICTs services' $=w_{o 5}=0.069$ and 'Pending unified/ converged licensing' $=w_{o 1}=0.034$ may be the last factors to be taken advantage of.

In the category of threats, a consistency ratio of, $\mathrm{CR}=0.059065161$, was obtained. Since it is less than 0.1 , the pair wise judgment for threats factors is consistent. Factor; 'Increased competition as a result of unified licensing' $=w_{T 3}$ with a rating of 0.291 , contributes most in the category of threats and it means strategies to fight competition has to be put in place by the company, since competition also impact on customer base of the company. Factor; 'Non-availability of CDMA customer premise equipment (CPEs) on the local market' $=w_{T 6}$ lies second as a threat factor to be addressed by the company, with a rating of 0.290 . Non availability of CDMA equipment in the market may cause customer dissatisfaction. Third on the rankings is the factor;

Limited availability of $4 \mathrm{G}$ frequencies (demand is high)' $=w_{T 5}$ with a rating of 0.218 . The factor is to be faced after the first two factors have been dealt with. Two factors; 'Other operators laying optical fiber on ZETDC lines' = $w_{T 1}$ and 'Power outages and Infrastructure vandalism (Causing network disruptions)' $=w_{T 2}$, lie fourth with a rating of 0.03 . This means that these factors have to be faced after facing the first three factors. Lastly on the rankings is the factor; 'Stagnation of the economy' $=w_{T 4}$ $=0.055$. This factor may be the last to be addressed by the company.

\subsection{Weights for Efficiency of Each Strategy in Taking Advantage of the Strengths Factors}

Considered are five strategies as per the decision makers' discretion. Below is the table for weights of the strategies in taking advantage of strengths factors.
Table 5. Weights for Efficiency of each strategy in taking advantage of the strength factors

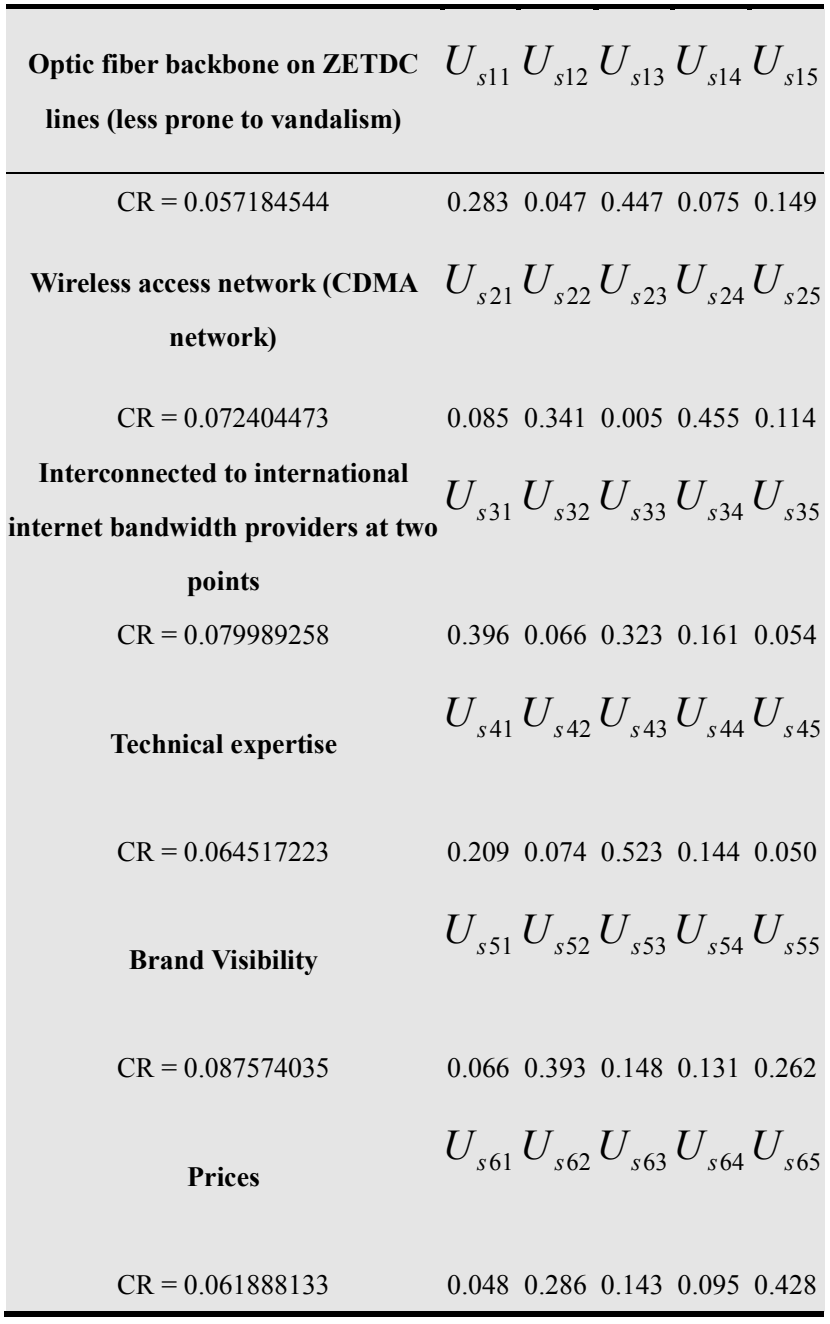

In terms of taking advantage of Optic fiber backbone on ZETDC lines (less prone to vandalism - high availability), strategy 3 (Ensure network reliability) is more efficient with a rating of $U_{s 13}=0.447$. The company should ensure rightful equipment is put in place (such as power backup utilities), to ensure network reliability. If the network is reliable customers will be satisfied, since the modern day internet based services are based on reliability. Strategy 1 (Network expansion and maintain product availability), is the second best with a rating of $U_{s 11}=0.0 .283$. By ensuring network reliability, the company should as well ensure expansion of its network. Review of pricing plans strategy lie third with a rating of $U_{s 15}=0.149$, innovation strategy lie fourth with a rating of $U_{s 14}=0.075$ and lastly mass marketing and customer database management lie fifth with a rating of $U_{s 12}=0.047$. This means that the company must review its prices, innovate and mass market after maintenance of network reliability and expansion. A consistency ratio of $\mathrm{CR}=0.057184544$ was obtained for the pair wise judgment and is acceptable since it is less than 0.1 . 
In terms of taking advantage of Wireless access network (CDMA network), strategy 4 (innovation/ diversification) is the most important, with a rating of $U_{s 24}=0.455$. This means that increasing the basket of the customer on top of the CDMA network, the company should innovate or diversify into other products. Strategy 2 (mass marketing and customer database management) lie second in terms of efficiency with a rating of $U_{s 22}=0.341$. This means that the company should innovate first and implement mass marketing whilst in the process of innovation. Review of pricing plans strategy lie third with a rating of $U_{s 25}=$ 0.114 . Obviously after innovation and mass marketing, the company should look into pricing options at its disposal. Since mass marketing and pricing may improve customer base and retention of customers, it would be advisable to implement network expansion and maintain product availability strategy (rated fourth most efficient with $U_{s 21}$ $=0.085$ and ensure network reliability (rated lastly, with $\left.U_{s 23}=0.005\right)$, in-order to cushion traffic congestion. Consistency ratio of $\mathrm{CR}=0.072404473$ was obtained and found acceptable since it is less than 0.1 .

In terms of taking advantage of the strength factor 'Interconnected to international internet bandwidth providers at two points', strategy 1 (network expansion and maintain product availability) is the most efficient with a rating of $U_{s 31}=0.396$. The company should expand its network from both points of connection and probably adopt the ring topology on its network sub and main links (including boosters). Second most efficient is strategy 3 (ensure network reliability) with a rating of $U_{s 33}=0.323$, meaning the company must not just expand its network but must also ensure network reliability. Reliability of the networks is what customers want. Third most efficient is a strategy 4 (innovation) with a rating of $U_{s 34}=0.161$. That is whilst in the process of network expansion and ensuring network reliability, the company should also introduce some other products. Innovation comes with mass marketing. Thus the fourth most efficient is mass marketing and customer database management with a rating of $U_{s 32}=0.066$. Lastly review of pricing plans is fifth most important with a rating of $U_{s 35}=0.054$. Consistency ratio of $\mathrm{CR}=0.079989258$ was obtained and is acceptable for the pair wise judgments since it is less than 0.1 .

In taking advantage of the strength factor 'Technical expertise' strategy 3 (ensure network reliability), with a rating of $U_{s 43}=0.523$ is the best. This means that the company should take advantage of technical expertise to ensure network reliability. Strategy 1 (network expansion and maintain product availability) with a rating of $U_{s 41}=$ 0.209 , is the second best. This means that the company should also take advantage technical expertise to expand its networks, whilst ensuring network reliability. Third most efficient in taking advantage of technical expertise is innovation with a rating of $U_{s 44}=0.144$. Fourth most efficient is strategy 2 (mass marketing and customer database management) with a rating of $U_{s 42}=0.074$. Meaning the company must mass market soon after innovation. Fifth is review of pricing plans with a rating of $U_{s 45}=0.050$. This means that efficient response rate to products faults and network disruptions plays an important part in pricing of services and products. A consistency ratio of $\mathrm{CR}=0.064517223$ was obtained and is considered acceptable since it is less than 0.1 .

In taking advantage of brand visibility, strategy 2 (mass marketing and customer database management strategy), with a rating of $U_{s 52}=0.393$ is the most important. The company should take advantage of brand visibility through marketing its products so as to improve its position in the market. Review pricing plans, lie second in terms of taking advantage of brand visibility with a rating of $U_{s 55}=$ 0.262 . The company may have improved revenues if it takes advantage of brand visibility. This strategy may be implemented simultaneously with mass marketing, though mass marketing is the most efficient. Third most efficient strategy is to ensure network reliability with a rating of $U_{s 53}=0.148$. This means that soon after or in the process of taking advantage of brand visibility through pricing, the company must ensure network reliability commensurate with pricing. Fourth most efficient strategy in taking advantage of brand visibility is innovation, with a rating of $U_{s 54}=0.131$. Meaning it follows after implementation of network reliability strategy. Fifth most efficient strategy is network expansion and maintain product availability with a rating of $U_{s 51}=0.066$. This strategy ensures that there is a balance between demand and supply of network services since the first prioritized strategies may increase demand. A consistency ratio of $\mathrm{CR}=0.087574035$ was obtained and is acceptable since it is less than 0.1 .

In taking advantage of prices, review pricing plans strategy with a rating of $U_{s 65}=0.428$ is the most efficient. Mass marketing and customer database management strategy, with a rating of $U_{s 62}=0.286$ is the second most efficient. Because of the company's reasonable prices, mass marketing may be used to retain and add more customers to already existing ones. Ensuring network reliability strategy is rated third most efficient with $U_{s 63}$ $=0.143$, meaning mass marketing and database management must be carried on whilst maintaining network reliability. Innovation is fourth most important with a rating of $U_{s 64}=0.095$ and network expansion and maintain product availability strategy is the fifth most efficient with a rating of $U_{s 61}=0.048$. A consistency ratio of $\mathrm{CR}=0.061888133$ was obtained and is considered 
acceptable, since it is less than 0.1 .

\subsection{Weights for Efficiency of Each Strategy in Lessening the Effect of the Weakness Factors}

Linear Programs for weights calculations and results are presented in Appendix 3. Below is a table for weights of strategies in terms of their efficiency in lessening weakness factors.

Table 6. Weights for Efficiency of each strategy in lessening the effect of the Weakness factors

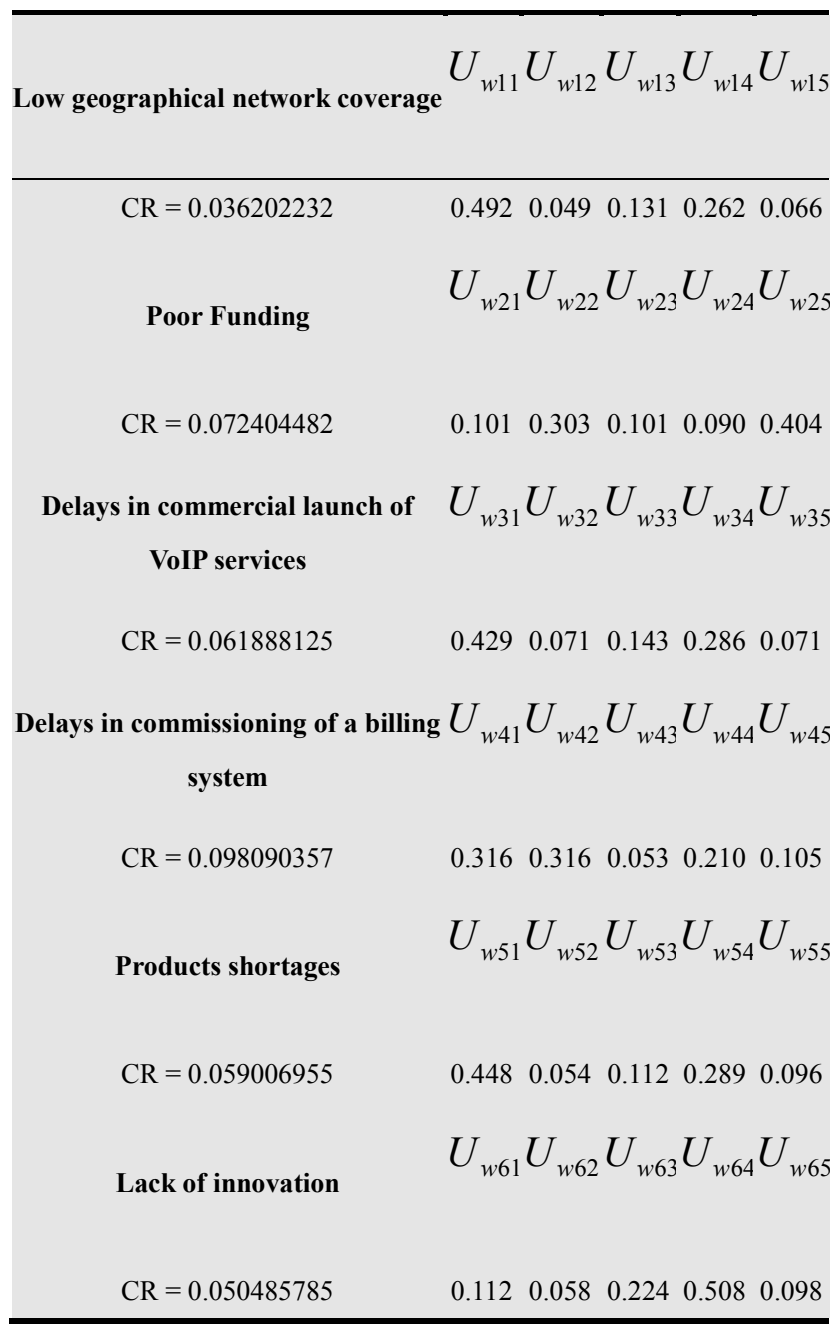

In terms of reducing the effects of weakness factor, low geographical coverage, strategy 1 (network expansion and maintain product availability) is the most efficient with a rating of $U_{w 11}=0.492$. The company should expand its network (physical and wireless), so as to lessen the weakness factor. Expansion must also come with product availability. Innovation strategy lie second with a rating of $U_{w 14}=0.262$. This means that technologies such as WiMAX base stations may be used. Third to be considered in terms of lessening low geographical coverage is to ensure network reliability with a rating of $U_{w 13}=0.131$. Meaning after expansion and innovation, the company should ensure reliability of its networks. Fourth most efficient is Review pricing plans strategy with a rating of $U_{w 15}=0.066$. This means that prices have to be reasonable for the company to have $6.6 \%$ chance of reducing the low geographical coverage factor consequences. Fifth efficient in lessening the weakness factor is strategy 2 (mass marketing and customer database management) with a rating of $U_{w 12}=0.049$. This means that the least the company can do to lessen the weakness factor is to mass market. A consistency ratio of $\mathrm{CR}=0.036202232$ was obtained and is acceptable since it is less than 0.1 .

In terms of lessening the weakness factor, 'funding', strategy 5 (review pricing plans) is most efficient with a rating of $U_{w 25}=0.404$. It should be considered first by the company, probably by review of tariffs (adding a certain profit margin). Strategy 2 (mass marketing and customer database management) with a rating of $U_{w 22}=0.303$ is the second most efficient. It means that the company may implement the strategy after consideration of strategy 5 . Strategies 1 and 3 (network expansion and maintain product availability and ensure network reliability) with rating $U_{w 21}=U_{w 23}=0.101$ lie third in terms of ratings. This means that they are a third option to be considered in lessening the effect of poor funding. Innovation may be the last one to be considered with a rating of $U_{w 24}=0.090$. A consistency of $\mathrm{CR}=0.072404482$ was obtained and is acceptable since it is less than 0.1

In lessening the effects of delays in commercial launch of VoIP services, strategy 1 (network expansion and maintain product availability) is the most efficient with a rating of $U_{w 31}=0.429$. It may be considered first since network expansion provides a platform for launch of VoIP services. Strategy 4 (innovation) with a rating of $U_{w 34}=$ 0.286 lie second. This means that it may be considered as second option in lessening the weakness factor. Innovation may not mean product innovation only, but the company may innovate some other network utilities in line with network expansion and maintenance of product availability. Ensure network reliability strategy lie third with a rating of $U_{w 33}=0.143$. This means that this strategy may be considered as third option in lessening the weakness factor. strategies 2 and 5 (mass marketing and customer database management and review pricing plans) both lie fourth with rating $U_{w 32}=U_{w 35}=0.071$. This means that they are both considered as fourth option in lessening the weakness factor. A consistency of CR $=0.061888125$ was obtained and is acceptable since it is less than 0.1 .

In terms of lessening the effect of delays in commissioning of a billing system, strategies 1 and 2 (network expansion and maintain product availability and mass marketing and Customer database management) both with a rating $U_{w 41}=U_{w 42}=0.316$ are the most efficient. They must be considered first. This means that billing 
system may only be implemented after being assured of having more customers. Small customer base may require simple computer programs. Innovation strategy lie second with a rating of $U_{w 44}=0.210$. This means that it may be considered as a second option. Thus probably having a team of computer programmers to work on codes and programs. Review of pricing plans strategy lie third with a rating of $U_{w 45}=0.105$. It may be a third consideration for the company, probably to fix some of its prices. Ensure network reliability may be the last one to be considered with a rating of $U_{w 43}=0.053$. A consistency ratio of $\mathrm{CR}=0.098090357$ was obtained and is acceptable since it is less than 0.1 .

In lessening the effect of products shortages, strategy 1 (network expansion and maintain product availability) is the most efficient with a rating $U_{w 51}=0.448$. It must be considered first. Innovation strategy lie second with a rating of $U_{w 54}=0.289$ and must be taken as a second option, probably venturing into some other internet related products. Ensure network reliability strategy lie third with a rating of $U_{w 53}=0.112$. This means it may be considered as a third option, though having $11.2 \%$ degree of efficiency. Review pricing plans strategy lie fourth with a rating of $U_{w 55}=0.096$. The company may take this strategy as a fourth option. Mass marketing and customer database management is the last strategy the company may implement with a rating of $U_{w 52}=0.054$. This is so because you cannot add more customers when you are experiencing product shortages. A consistency ratio of CR $=0.059006955$ was obtained and is considered acceptable since it is less than 0.1 .

In lessening the effects of lack of innovation, strategy 4 (innovation) is the most efficient with a rating of $U_{w 64}=$ 0.508 . The company should consider it first and it has to innovate. Strategy 3 (ensure network reliability) lie second with a rating of $U_{w 63}=0.224$. It has to be considered as a second option. Strategy 1 (network expansion) is the third most efficient with a rating of $U_{w 61}=0.112$. It is a third option for the company and also encompasses innovation in it. Review of pricing plans lie fourth with a rating of $U_{w 65}=0.098$. This means it is the fourth one to be considered in lessening the effect of lack of innovation. Least strategy on ratings to be considered is mass marketing and customer database management with a rating of $U_{w 62}=0.058$. A consistency ratio of $\mathrm{CR}=$ 0.050485785 was obtained and is acceptable since it is less than 0.1 .

\subsection{Weights for Efficiency of Each Strategy in Taking Advantage of the Opportunities Factors}

Linear Programs for weights calculations were used.
Below is a table for weights of strategies in terms of their efficiency in taking advantage of opportunities factors.

Table 7. Weights for Efficiency of each strategy in taking advantage of the Opportunities factors

\begin{tabular}{|c|c|}
\hline Pending unified/converged licensing & $U_{o 11} U_{o 12} U_{o 13} U_{o 14} U_{o 15}$ \\
\hline $\mathrm{CR}=0.070027491$ & $\begin{array}{lllll}0.409 & 0.128 & 0.07 & 0.350 & 0.043\end{array}$ \\
\hline Dollarization of the economy & $U_{o 21} U_{o 22} U_{o 23} U_{o 24} U_{o 25}$ \\
\hline $\mathrm{CR}=0.081811678$ & $\begin{array}{lllll}0.119 & 0.048 & 0.238 & 0.119 & 0.476\end{array}$ \\
\hline $\begin{array}{l}\text { 'Look east policy’ - have Asian } \\
\text { equipment vendors locally }\end{array}$ & $U_{o 31} U_{o 32} U_{o 33} U_{o 34} U_{o 35}$ \\
\hline $\mathrm{CR}=0.098090357$ & $\begin{array}{lllll}0.367 & 0.052 & 0.367 & 0.122 & 0.092\end{array}$ \\
\hline A big market & $U_{o 41} U_{o 42} U_{o 43} U_{o 44} U_{o 45}$ \\
\hline $\mathrm{CR}=0.07473108$ & $\begin{array}{lllll}0.174 & 0.401 & 0.100 & 0.058 & 0.267\end{array}$ \\
\hline $\begin{array}{l}\text { Increasing acceptance of } \\
\text { bandwidth/ICTs services }\end{array}$ & $U_{o 51} U_{o 52} U_{o 53} U_{o 54} U_{o 55}$ \\
\hline $\mathrm{CR}=0.099713928$ & $\begin{array}{lllll}0.153 & 0.031 & 0.350 & 0.117 & 0.349\end{array}$ \\
\hline $\begin{array}{l}\text { POTRAZ installing passive } \\
\text { infrastructure in remote areas }\end{array}$ & $U_{o 61} U_{o 62} U_{o 63} U_{o 64} U_{o 65}$ \\
\hline $\mathrm{CR}=0.061888133$ & $\begin{array}{lllll}0.057 & 0.343 & 0.343 & 0.171 & 0.086\end{array}$ \\
\hline
\end{tabular}

In taking advantage of opportunities factor; 'pending unified/ converged licensing', strategy 1 (network expansion and maintain product availability) is the most efficient, with a rating of $U_{o 11}=0.409$. It has to be considered first since infrastructure availability may provide a platform for the launch of multi-services sectioned in converged licenses. Strategy 4 (innovation) is the second most efficient with a rating of $U_{o 14}=0.350$. It has to be considered as a second option. In the event of considering it, the company may implement innovative plans so as to take advantage of unified service provision. Third most important is strategy 2 (mass marketing and customer database management) with a rating of $U_{o 12}=$ 0.128 and it has to be considered as third option. Fourth most important is strategy 3 (ensure network reliability) with a rating of $U_{o 13}=0.07$. Fifth most efficient strategy is strategy 5 (review pricing plans) with a rating of $U_{o 15}=$ 0.043 . The strategy may be considered as last option to take 
advantage of the opportunity factor. A consistency ratio of $\mathrm{CR}=0.070027491$ was obtained and considered acceptable since it is less than 0.1 .

In taking advantage of dollarization of the economy, strategy 5 (review pricing plans) is the most efficient with a rating of $U_{o 25}=0.475$. The company must consider it first. Demand based or cost based pricing schemes may be implemented (with customers in mind as well, since the company is trying to reduce customer churn). Strategy 3 (ensure network reliability) lie second with a rating of $U_{o 23}=0.238$ and must be the second option to be considered by the company. Readily available forex means that equipment importation is facilitated to ensure network reliability. Strategies 1 and 4 (network expansion and maintain product availability and innovation) with rating $U_{o 21}=U_{o 24}=0.119$, are third most efficient. This means that these strategies are a third option in taking advantage of dollarization of the economy. Strategy 2 (mass marketing and customer database management) with a rating of $U_{o 22}=0.048$ is the fourth most efficient and should be treated as the last option to take advantage of dollarization. A consistency ratio of $\mathrm{CR}=0.081811678$ was obtained and is considered acceptable since it is less than 0.1 .

In taking advantage of the opportunities factor 'look east policy' - have Asian equipment vendors locally' strategy 1 (network expansion and maintain product availability) with a rating of $U_{o 31}=0.367$. The strategy is the one to be considered first. Localization of such operators means ease of access to readily available vendors. Strategy 3 (ensure network reliability), have the same rating as well $U_{o 33}=$ 0.367 and must be simultaneously prioritized with the strategy of network expansion. Ease of access to equipment and other network utilities ensure network reliability, hence the need to take advantage of the opportunity to expand and ensure network reliability. Strategy 4 (innovation) is the second most efficient strategy with a rating of $U_{o 34}=$ 0.122 . Looking east and having these vendors locally may pave way for transfer of technology and innovative ideas being mooted. Strategy 5 (review pricing plans) lie third with a rating of $U_{o 35}=0.092$. It may be the third option to be considered by the company. Cheaper equipment from Asia may have an effect on pricing. The lower the prices of the company, the more customers the company has, though it may not always be the case. Strategy 2 (mass marketing and customer database management) lie fourth with a rating of $U_{o 32}=0.052$. This strategy is the least to be considered. A consistency ratio of $\mathrm{CR}=0.098090357$ was obtained and considered acceptable since it is less than 0.1 .

In terms of taking advantage of a big market, strategy 2 (mass marketing and customer database management) is the most efficient with a rating of $U_{o 42}=0.401$. It has to be the first consideration of the company. Mass marketing may capture a larger market share, overriding the effect of customer churn. Strategy 5 (review pricing plans) lie second with a rating of $U_{o 45}=0.267$ and has to be the second option to be considered by the company. Strategy 1 (network expansion and maintain product availability) is the third most efficient with a rating $U_{o 41}=0.174$. It may be taken as the third option and a big market may mean increased demand for network services. Strategy 3 (ensure network reliability) lie fourth with a rating of $U_{o 43}=0.100$ and is to be a fourth option to be considered. Reliable network may entice new customers and already existing ones to stay in the system. Strategy 4 (innovation) with a rating of $U_{o 44}=0.058$ is the fifth most efficient and may be considered as the last option in the perking. A consistency ratio of $\mathrm{CR}=0.07473108$ was obtained and is considered acceptable since it is less than 0.1 .

In taking advantage of increasing acceptance of bandwidth/ICT's services by the market, strategy 3 (ensure network reliability), with a rating of $U_{o 53}=0.350$, is the most efficient. It has to be the first consideration of the company in taking advantage of the opportunity. This means that increased acceptance instigate hunger for internet services. Thus a reliable network provider may be the rightful operator for the customer. Strategy 5 (review pricing plans) lie second with a rating of $U_{o 55}=0.349$ and has to be considered as a second option to take advantage of the opportunity. Reasonable prices draw more customers to the organization. Strategy 1 (network expansion and maintain product availability) lie third with a rating of $U_{o 51}=0.153$. It has to be a third consideration for the company. Network expansion may help cushion ever increasing demand for the service. Strategy 4 (innovation) lie fourth with a rating of $U_{o 54}=0.117$ and has to be taken as a fourth option for the company in taking advantage of increasing acceptance of bandwidth services by the market. Strategy 2 (mass marketing and customer database management) is the fifth most efficient in taking advantage of the opportunity, with a rating of $U_{o 52}=0.031$ and has to be considered as the last option. A consistency ratio of CR $=0.099713928$ was obtained and considered acceptable since it is less than 0.1 .

In taking advantage of the POTRAZ initiative of installing passive infrastructure in remote areas, strategy 2 and 3 (mass marketing and customer database management and ensure network reliability) are the most efficient with a rating of $U_{o 62}=U_{o 63}=0.343$. They must be prioritized first. The initiative implies infrastructure sharing, hence the need to mass market and ensure network reliability. Strategy 4 (innovation) lie second with a rating of $U_{o 64}=$ 0.171 and should be second to be considered and prioritized Innovation may help the company have a competitive advantage in the environment of infrastructure sharing. Strategy 5 (review pricing plans) is the third most efficient in taking advantage of the POTRAZ initiative. Prices may 
be used as a competitive tool as well. Strategy 1 (network expansion and maintain product availability) is the least efficient with a rating of $U_{o 61}=0.057$ and the least to be considered, since POTRAZ initiative ensures network infrastructure availability. A consistency ratio of $\mathrm{CR}=$ 0.0980903587 was obtained and considered acceptable, since it is less than 0.1 .

\subsection{Weights for Efficiency of Each Strategy in Facing the Threats Factors}

Linear Programs for weights calculations and results are presented in Appendix $\$ 3 \$$. Following is the table for weights of strategies in terms of their efficiency in facing the Threats factors.

Table 8. Weights for Efficiency of each strategy in facing the Threats factors

\begin{tabular}{|c|c|}
\hline \multicolumn{2}{|c|}{$\begin{array}{l}\text { Other operators laying optical fiber } U_{T 11} U_{T 12} U_{T 13} U_{T 14} U_{T 15} \\
\quad \text { on ZETDC lines }\end{array}$} \\
\hline $\mathrm{CR}=0$ & $\begin{array}{lllll}0.508 & 0.054 & 0.269 & 0.102 & 0.067\end{array}$ \\
\hline $\begin{array}{l}\text { Power outages and Infrastructure } \\
\text { vandalism (causing network } \\
\text { disruptions) }\end{array}$ & $U_{T 21} U_{T 22} U_{T 23} U_{T 24} U_{T 25}$ \\
\hline $\mathrm{CR}=0.07565158$ & $\begin{array}{lllll}0.167 & 0.042 & 0.583 & 0.125 & 0.083\end{array}$ \\
\hline \multicolumn{2}{|c|}{$\begin{array}{l}\text { Increased Competition as a result of } U_{T 31} U_{T 32} U_{T 33} U_{T 34} U_{T 35} \\
\text { unified licensing }\end{array}$} \\
\hline $\mathrm{CR}=0.092832232$ & $\begin{array}{lllll}0.045 & 0.312 & 0.312 & 0.110 & 0.221\end{array}$ \\
\hline Stagnation of the economy & $U_{T 41} U_{T 42} U_{T 43} U_{T 44} U_{T 45}$ \\
\hline $\mathrm{CR}=0.072404464$ & $\begin{array}{lllll}0.082 & 0.122 & 0.490 & 0.061 & 0.245\end{array}$ \\
\hline $\begin{array}{l}\text { Limited availability of } \mathbf{4 G} \\
\text { frequencies (demand is high) }\end{array}$ & $U_{T 51} U_{T 52} U_{T 53} U_{T 54} U_{T 55}$ \\
\hline $\mathrm{CR}=0.061888142$ & $\begin{array}{lllll}0.152 & 0.038 & 0.405 & 0.304 & 0.101\end{array}$ \\
\hline \multicolumn{2}{|c|}{$\begin{array}{l}\text { Non-availability of CDMA customer } \\
\text { premise equipment (CPEs) on the }\end{array} U_{T 61} U_{T 62} U_{T 63} U_{T 64} U_{T 65}$} \\
\hline local market & \\
\hline $\mathrm{CR}=0.089950982$ & $\begin{array}{lllll}0.233 & 0.058 & 0.116 & 0.465 & 0.127\end{array}$ \\
\hline
\end{tabular}

In facing threat factor 'other operators laying optical fiber on ZETDC lines', strategy 1 (network expansion and maintain product availability) is the most efficient with a rating of $U_{T 11}=0.508$. The company may exhaust all platforms on power lines, laying its fiber optics. Strategy 3 (ensure network reliability) is the second most efficient with a rating of $U_{T 13}=0.269$. The strategy has to be considered as the second option and implies even if other operators happen to lay fiber on ZETDC lines, reliability of the company's networks may stand as a competitive advantage. Innovation strategy is third most efficient with a rating of $U_{T 14}=0.102$. It has to be prioritized as third option. Strategy 5 (review pricing plans) is the fourth most efficient in facing the threat factor. Prices may stand as a competitive edge. Least most efficient is strategy 2 (mass marketing and customer database management) with a rating of $U_{T 12}=0.054$. Meaning it will be the last to be considered. A consistency ratio of $\mathrm{CR}=0.086870982$ was obtained and considered acceptable, since it is less than 0.1 .

In facing the threat of Power outages and infrastructure vandalism, strategy 3 (ensure network reliability) is the most efficient with a rating of $U_{T 23}=0.583$. It means it may be the first strategy to be adopted. Equipment such as generators may be bought and put in place to cushion power outages. Strategy 1 (network expansion and maintain product availability) is the second most efficient with a rating of $U_{T 21}=0.167$. Ring topologies may be adopted in expanding networks, so as to redirect network traffic in times of vandalism. Strategy 4 (innovation) is the third most efficient with a rating of $U_{T 24}=0.125$ and has to be taken as a third option. The company may innovate network security utilities. Strategy 5 (review pricing plans) is the fourth most efficient with a rating of $U_{T 25}=0.083$ and has to be considered as fourth option. Strategy 2 (mass marketing and customer database management) is the least in terms of efficiency in facing the threat factor with a rating of $U_{T 22}=0.042$. It may be considered as the last option. A consistency ratio of $\mathrm{CR}=0.07565158$ was obtained and considered acceptable since it is less than 0.1 .

In facing increased competition as a result of unified licensing, strategies 2 and 3 (mass marketing and customer database management and Ensure network reliability) are the most efficient with a rating of $U_{T 32}=U_{T 33}=0.312$. They have to be prioritized first by the company. Strategy 5 (review pricing plans) lie second with a rating of $U_{T 35}=$ 0.221 and has to be prioritized as a second option. Reasonable prices may fight competition. Strategy 4 (innovation) is the third most efficient in facing the threats factor, with a rating of $U_{T 34}=0.110$ and it must be considered as the fourth option for the company. Strategy 1 (network expansion and maintain product availability) is the fifth most important with a rating of $U_{T 31}=0.045$ and has to be the last one to be considered. A consistency ratio of $\mathrm{CR}=0.092832232$ was obtained and is acceptable, since it is less than 0.1 .

In facing stagnation of the economy, the company should consider strategy 3 (ensure network reliability) with a rating of $U_{T 43}=0.490$. It has to be prioritized first. 
Strategy 5 (review pricing plans) lie second with a rating of $U_{T 45}=0.245$. The strategy is the second best and has to be prioritized as the second option. Reasonable prices may maintain customer base. Strategy 2 (mass marketing and customer database management), with a rating of $U_{T 42}=$ 0.122 , is the third best and has to be prioritized as third option. strategy 1 (network expansion and maintain product availability) is the fourth best with a rating of $U_{T 41}=$ 0.082 and the least efficient is strategy 4 (innovation) with a rating of $U_{T 44}=0.061$. A consistency Ratio of $\mathrm{CR}=$ 0.072404464 was obtained and is acceptable since it is less than 0.1 .

In facing the threat of limited availability of $4 \mathrm{G}$ frequencies, Strategy 3 (ensure network reliability) is the best with a rating of $U_{T 53}=0.405$, meaning maintaining quality on what the company has. Strategy 4 (innovation) lie second with a rating of $U_{T 54}=0.304$ and may be prioritized as a second option. It means probably innovating into some other frequency bands. Strategy 1 (network expansion and maintain product availability) is the third most efficient, with a rating of $U_{T 51}=0.152$ and may be a third priority for the company. Strategy 5 (review pricing plans) is fourth most efficient with a rating of $U_{T 55}=0.101$ and has to be treated as fourth option. Strategy 2 (mass marketing and customer database management) is the least efficient with a rating of $U_{T 52}=$ 0.038 . A consistency ratio of $\mathrm{CR}=0.061888142$ was obtained and considered acceptable, since it is less than 0.1 .

In facing the threat factor of Non-availability of CDMA customer premise equipment (CPEs) on the local market, strategy 4 (innovation) is the most efficient with a rating of $U_{T 64}=0.465$. It is the one that the company may adopt and prioritize first. The company should innovate. Second best is strategy 1 (network expansion and maintain product availability) with a rating of $U_{T 61}=0.233$ and is a second priority. The company must maintain a balance between product availability and demand. Third best is strategy 5 (review pricing plans) with a rating of $U_{T 65}=0.127$. Fourth best is strategy 3 (ensure network reliability) with a rating of $U_{T 63}=0.116$ and has to be considered as fourth option. Least efficient is strategy 2 (mass marketing and customer database management) with a rating of $U_{T 62}=$ 0.058 . It has to be the last to be prioritized. A consistency ratio of $\mathrm{CR}=0.089950982$ was obtained and considered acceptable since it is less than 0.1 .

\subsection{Generalized Sensitivity Analysis}

Sensitivity analysis is performed on the input to the model. This means that it is performed on the pair-wise judgment matrix. A decision maker might be interested in answering the following questions: What entry in the pair-wise comparison matrix should be changed to reduce inconsistencies? By how much should the entry be changed?

Suppose that a decision maker estimates an entry incorrectly and put it into the pair-wise comparison matrix, Linear Programming models identify these inconsistencies. In the first stage Linear Program, the values of the dual variables at optimality provide an indication of incorrect entries in the pair-wise comparison matrix. The objective function in the first stage Linear Program provides a measure of inconsistency, the larger the value, the more inconsistent the pair-wise matrix will be. Thus the dual variable that corresponds to each constraint in the first stage Linear Program measures the amount by which the inconsistency value increases if the corresponding right hand side constraint $\left(a_{i j}\right)$ increases by 1 unit.

Since we are in natural logarithm space, a dual variable with value $k$ at optimality means that the objective function value (inconsistency value) increases by $k$ units when corresponding $a_{i j}$ increases by a factor of $e$, the base of the natural logarithm. This means that it is possible to identify which $a_{i j}$ to change in order to decrease inconsistency value by the greatest amount. A dual variable with a negative value indicates that $a_{i j}$ should be increased, while a positive value means that $a_{i j}$ should be decreased.

\subsection{Global Values for Strategies}

\subsubsection{Strategy 1 - Network Expansion and Maintain Product Availability}

$$
\begin{aligned}
v_{j} & =w_{s} \sum_{i=1}^{m s} w_{s i} u_{s i, j}+w_{w} \sum_{i=1}^{m w} w_{w i} u_{w i, j}+w_{o} \sum_{i=1}^{m o} w_{o i} u_{o i, j}+w_{T} \sum_{i=1}^{m t} w_{T i} u_{T i, j} \\
& =0.549 \sum_{=1}^{m s} w_{s i} u_{s i, 1}+0.091 \sum_{=1}^{m w} w_{w i} u_{w i, 1}+0.30 \sum_{=1}^{m o} w_{o i} u_{o i, 1}+0.06 \sum_{=1}^{n t} w_{T i} u_{T i, 1} \\
& =0.180468577
\end{aligned}
$$

The global value of 0.180468577 means that the strategy (network expansion and maintain product availability) has an efficiency level of $18.05 \%$, of reducing customer churn.

\subsubsection{Strategy 2 - Mass marketing and Customer Database Management}

$$
\begin{aligned}
v_{2} & =w_{s} \sum_{i=1}^{m s} w_{s i} u_{s i, 2}+w_{w} \sum_{i=1}^{m w} w_{w i} u_{w i, 2}+w_{o} \sum_{i=1}^{m o} w_{o i} u_{o i, 2}+w_{T} \sum_{i=1}^{m t} w_{T i} u_{T i, 2} \\
& =0.549 \sum_{i=1}^{m s} w_{s i} u_{s i, 2}+0.091 \sum_{i=1}^{m w} w_{w i} u_{w i, 2}+0.30 \sum_{i=1}^{m o} w_{o i} u_{o i, 2}+0.06 \sum_{i=1}^{m t} w_{T i} u_{T i, 2} \\
& =0.193364195
\end{aligned}
$$

The global value of 0.193364195 means that the strategy (network expansion and maintain product availability) has an efficiency level of $19.34 \%$, of reducing customer churn.

\subsubsection{Strategy 3 - Ensure Network Reliability}

$$
\begin{aligned}
v_{3} & =w_{s} \sum_{i=1}^{m s} w_{s i} u_{s i, 3}+w_{w} \sum_{i=1}^{m w} w_{w i} u_{w i, 3}+w_{o} \sum_{i=1}^{m o} w_{o i} u_{o i, 3}+w_{T} \sum_{i=1}^{m t} w_{T i} u_{T i, 3} \\
& =0.549 \sum_{i=1}^{m s} w_{s i} u_{s i, 2}+0.091 \sum_{i=1}^{m w} w_{w i} u_{w i, 3}+0.30 \sum_{i=1}^{m o} w_{o i} u_{o i, 3}+0.06 \sum_{i=1}^{m t} w_{T i} u_{T i, 3}
\end{aligned}
$$




\section{$=0.248509996$}

The global value of 0.248509996 means that the strategy (ensure network reliability) has an efficiency level of $24.85 \%$, of reducing customer churn.

\subsubsection{Strategy 4 - Innovation (Diversification)}

$$
\begin{aligned}
v_{4} & =w_{s} \sum_{i=1}^{m s} w_{s i} u_{s i, 4}+w_{w} \sum_{i=1}^{m w} w_{w i} u_{w i, 4}+w_{o} \sum_{i=1}^{m o} w_{o i} u_{o i, 4}+w_{T} \sum_{i=1}^{m t} w_{T i} u_{T i, 4} \\
& =0.549 \sum_{=1}^{m s} w_{s i} u_{s i, 4}+0.091 \sum_{i=1}^{m w} w_{w i} u_{w i, 4}+0.30 \sum_{i=1}^{m o} w_{o i} u_{o i, 4}+0.06 \sum_{i=1}^{m t} w_{T i} u_{T i, 4} \\
& =0.16607826
\end{aligned}
$$

The global value of 0.16607826 means that the strategy (ensure network reliability) has an efficiency level of $16.61 \%$, of reducing customer churn.

\subsubsection{Strategy 5 - Review pricing Plans}

$$
\begin{aligned}
v_{5} & =w_{s} \sum_{i=1}^{m s} w_{s i} u_{s i, 5}+w_{w} \sum_{i=1}^{m w} w_{w i} u_{w i, 5}+w_{o} \sum_{i=1}^{m o} w_{o i} u_{o i, 5}+w_{T} \sum_{i=1}^{m t} w_{T i} u_{T i, 5} \\
& =0.549 \sum_{i=1}^{m s} w_{s i} u_{s i, 5}+0.091 \sum_{=1}^{m w} w_{w i} u_{w i, 5}+0.30 \sum_{i=1}^{m o} w_{o i} u_{o i, 5}+0.06 \sum_{i=1}^{m t} w_{T i} u_{T i, 5} \\
& =0.210738922
\end{aligned}
$$

The global value of 0.210738922 means that the strategy (ensure network reliability) has an efficiency level of $21.07 \%$, of reducing customer churn.

\subsection{Normalization}

$$
\frac{V_{j}}{\sum_{j=1}^{5} V_{j}} \text { The formula is given by: }
$$

The following is a table for ranked strategies in terms of normalized weights.

Table 9 . Strategies ranking in terms of normalized weights

\begin{tabular}{ccr}
\hline Rank & Strategy & Weight \\
\hline 1 & Ensure network reliability & 0.248718932 \\
2 & Review pricing plans & 0.210916102 \\
& Mass marketing and Consumer Database & 0.193526767 \\
3 & management & 0.180620307 \\
4 & Network expansion and maintain product availability & 0.166217891 \\
5 & Innovation (Diversification) & 0.10 \\
\hline
\end{tabular}

\subsection{Optimal Strategy}

The company has to ensure network reliability so as to reduce customer churn, since the strategy is the one with highest efficiency rate of $24.8 \%$. Resources that ensure network reliability should be put in place and allocated in an optimal way.

\section{Summary, Conclusions and Recommendations}

The study investigated the use of the combination of SWOT analysis, Analytic Hierarchy Process and Linear Programming techniques in the area of strategic management and formulation for telecoms companies in Zimbabwe. The main aim was to formulate a model that would be used in strategy formulation. From chapter three, the researcher managed to link up SWOT analysis, AHP and Linear Programming to formulate strategies for telecoms companies. It is in chapter four that the robustness of the model formed was analyzed to answer the research questions.

From the model, it was established that the case study company should adopt the strategy of ensuring network reliability. The efficiency level was found to be $24.87 \%$. The model showed that review pricing plans strategy (with efficiency level of $21.09 \%$ may be adopted together with insurance of network reliability, since the difference in efficiency is not so significant. The researcher noted the strength of AHP in selection and Linear programming in weight calculations. It was also noted that SWOT factors of the company are the ones that determine the rate of customer churn.

The company should consider quantitative analysis in process of decision making. This reduces time and subjectivity in decision making. Considering the optimal strategy of ensuring network reliability, the company should ensure that all the necessary resources are put in place to achieve goals of the strategy. Resources such as advanced network utilities, power back ups and rapid technical response set up should be put in place. Other strategies may come in as aggregatory/make weight to the optimum strategy. It will not necessarily mean that lowly ranked strategies have to be neglected, but rather be considered as per their efficiencies in the perking order. The company should also consider input from subordinates without portfolios/ lower level subordinates to diversify input to decision making. Consideration of different views from different people may require the use of the established model; hence the company should consider its use. The researcher strongly recommends the commissioning of the use of the model in strategy formulation.

For future research, the models for strategy implementation may be mooted. These models may be used soon after coming up with a set of optimal strategies. Limitations of the study

Data is to be obtained from PowerTel Communications Harare region only because of costs and time constraints associated with the study, but in future other regional sections have to be considered as well, as input to the study need to be diversified.

The research is constrained by time and cost associated with travelling to get the data.

\section{References}

[1] J. Ahn, S. Han, and Y. Lee ,2006, Customer chutn analysis: churn determinants and mediation effects of partial defection in the Korea mobile service industry, Telecommunications Policy, 30(10-11), pp.552-568 
[2] J. Ahn, S. Han, and Y. Lee, 2006, Telecommunications Policy 30, 552-568 [Online]. Available: http://pages.stern.nyu.edu/ shan2/customerchurn.pdf [29/11/12]

[3] Attensity Telecom Industry Report, 2011, [Online]. Available: www.attensity.com/wp-content/uploads/2011/03/Telecomind ustryreport $\backslash$ March2011.pdf [22/04/13]

[4] A. Berson, S. Smith, and K. Thearling, 2002, Building Data Mining Applications for CRM: McGrawHill, New York.

[5] Business Dictionary, 2012.

[6] M. J. Bogdanoff, 2009. Masters theses; “'Supplier evaluation using analytic hierachy process".[online]. Available:https://www.doria.fi/bitstream/handle/10024/4464 6/nbnfi-fe200903191246.pdf? sequence $=3$ [25/04/13]

[7] B. Chandran, B. Golden, and E. Wasil, 2005, Computetrs and Operations Research 32, 2235-2254 [Online]. Available:www.knu.edu.tw/lecture/2005-08-09/methodolog y/LPmodels.pdf [22/04/13].

[8] R, Dass and J. Rumit, "An Analysis of the factors causing telecom churn: First Findings" 2011. AMCIS 2011 Proceedings. $\quad$ Paper $2 . \quad$ Available: http://aisel.aisnet.org/amcis2011_submissions/2.

[9] P. Dwivedi and J.R.R. Alavalapati, 2009. Stakeholders' perceptions on forest biomass-based bioenergy development in the Southern US. Energy Policy, 37, 1999-2007.

[10] D. B. Embling, 2012, Global mobile churn hits record high [online].

Available: www.telecomasia.net/content/global-mobile-churn-hits-reco rd-high [22/04/13]

[11] E. Forman, and S. Gass, 2008. The analytic hierachy process. p86

Available:http://mdm.gwu.edu/forman/ahpexpo.zip [24/04/13].

[12] C. Geppert, 2002, Customer Churn Management: Retaining high-margin customers with customer relationship management techniques:KPMG and associates. http://www.mickinsey.com/practices/marketing/ourknowled ge [29/11/12]

[13] F. Gurbuz, 2010. A'WOT analizi-Erciyes Universitesi Endustri Muhendisligi Bolumu uygulamasi [Online], Erciyes Universitesi Fen Bilimleri Enstitusu Dergisi, 26(4): 369-378, Kayseri,

http://fbe.erciyes.edu,tr/MKA-2005/Dergi/2010-vol126-no-4 /MAKALE7/FULL.pdf,Access:11.04.2011.

[14] T. Hill and R. Westbrook, (1997): "SWOT Analysis: It's Time for a Product Recall," Long Range Planning, (30), 46-52.

[15] A. Kandakoglu, I. Akgun and Y. I. Yopcu, 2007. Strategy development and evaluation in the Battlefield using quantified SWOT analytical method [online]. $9^{\text {th }}$ International Symposium on the Analytical Hierarchy Process (August 2-6 2007, Vina del Mar, Chile)Online Proceedings, http://chile2007.isahp.org/,Access:01.01.2010.

[16] J. Kangas, M. Pesonena, M. Kurttila and M. Kajanus 2001. A'WOT: Integrating the AHP with SWOT analysis [Online]. Sixth International Symposium on the Analytic Hierarchy Process- ISAHP2001 (August 2-4, 2001, Bern, Switzerland),
189-198, http://www.isahp.org/2001Proceedings/Papers/037-P.pdf,Ac cess:20.01.2001.

[17] P. Kendall, "Wireless operator performance benchmarking Q4 2011,” Boston Marriot Copley, pp. 125, April 052012.

[18] M. K. Kim, \& D. H. Jeong (2004). The effects of customer satisfaction and switching barriers on customer loyalty in Korean mobile telecommunication services. Telecommunications Policy, 28(2). 145158.

[19] A. A. Kojo, 2011, Predicting customer churn in the mobile telecommunication industry, A case study of MTN Ghana [Online].

Availabe:dspace.knust.edu.gh:8080/jspui/bitstream/1234567 89/4431/1/kojoAbiw-Abaidoo.pdf

[20] Last Quarterly PowerTel Business Report, 2012.

[21] S. A. Nelsin, S. Gupta,W. Kamakura,J. Lu, and C. Mason, 2004, Defective detection: Improving prediction accuracy of customer churn models, [online] Available: http://www,crmlandmark.com/library/customerchurnpdf $[22 / 04 / 13]$.

[22] E. E. Osuna, and A. Aranda, 2007, combining SWOT and AHP techniques for strategic planning [Online]. Available: www.isahp.org/2007Proceedings/Papers/workingsessions/D evelopmentplanning/CombiningSWOTandAHP.pdf [29/11/12]

[23] PWC, 2011. Curing customer churn [Online]. Available:www.com/en-us/us/increasing-it-effectiveness/ass erts/curing-customer-churn.pdf [22/04/13].

[24] T. L. Saaty, (1980), The Analytic Hierarchy Process, New York: McGraw Hill. International, Translated to Russian, Portuguese, and Chinese, Revised editions, Paperback (1996, 2000), Pittsburgh: RWS Publications.

[25] T. L. Saaty, and Vargas, L, G., 2000. Models, Methods, Concerpts and Applications of the Analytic Hierachy Process: Fifth edition. Springer, ISBN 978 - $0792372677.352 p$

[26] T. L. Saaty, and Vargas, L, G., 2012. Models, Methods, Concerpts and Applications of the Analytic Hierachy Process; International series in operations research and management science 175. Springer Science + Business media, New York.

[27] H. Shinno, H. Yoshioka, S. Marpaung and S. Hachiga, 2006. Quantitative SWOT analysis on global competitiveness on machine tool industry. Journal of Engineering Design, 17(3): 251-253.

[28] R. Siber, (1997). Combining the churn phenomenon, Telecommunications, 31(10), 7781.

[29] Steps in strategy formulation process [Online]. Available:www.managementstudyguide.com/strategy-formu lation-process.htm [22/04/13]

[30] D.M. Szemanski, S. G. Bharadwaj, P. R. Varadarajan. 1993, "Standardisation versus adaptation of international marketing strategy", journal of marketing 57, pp.17-33

[31] TEM Journal, 2012. Volume 1, Number 42012 [online]. Available:http://www.academia.edu/3019214/Strategy\deve lopment $\backslash$ by $\backslash$ using $\backslash S W O T \backslash-\backslash$ AHP

[32] H. Vadada, 2012, Wireless churn, metrices and big data [Online]. 
Available:www.telecom-cloud.net/wireless-churn-metrics-a nd-big-data/

[33] P. Van Gelder, D. Proske, and H. Vrijling 2009. Proceedings of the 7th International Probabilistic Workshop, Delft [online].

Available:http://books.google.co.zw/books?id=z4be05g9Xd 8C $\backslash \& p g=P A 491 \backslash \& \operatorname{lpg} \backslash \backslash$

$=$ PA491 $\backslash \&$ dq $=$ Van + gelder -+ AHP $\backslash \&$ source $=b l$

\\&ots=IUaE3t7UFw \

l\&sig=FZ2a4nGPq9WeKToH5aR7pO507Kc $\ \& h l=e n \backslash \& s a=$
$\mathrm{X} \backslash$ \&ei $=$ oGJ5Uca $\quad 9 P M 62 h A f J p Y D 4 A Q \backslash \& v e d=\backslash \backslash$ 0CDIQ6AEwAQ $\backslash \# \mathrm{v}=$ onepage\&q= $=\mid \% 20$ gelder- $\mid \% 20 \mathrm{AHP} \backslash \&$ $\mathrm{f}=\mathrm{false}$

[34] E. Yilmaz, 2007. A'WOT teknigikullanarak katilimci yakmasimla proje delerlendirmesi [online]. Doa Dergisi (Journal of Doa),13: 1-16, Dogu Akdeniz Ormancilik Arastrirma Mudurlugu, Mersin, www.doa.gov.tr/doadergisi/doa13/AWOT\%20.pdf,Access:2 5.02.2011. 